\title{
A consumación sexual do amor co monstro no conto de fadas moderno The Shape of Water do cineasta Guillermo del Toro
}

\author{
Rocío G-Pedreira \\ [Recibido, 15 setembro 2019; aceptado, 3 novembro 2019] \\ http://dx.doi.org/10.15304/bgl.55.6278
}

RESUMO O mito do amor romántico entre a monstruosidade e o ser humano foi unha constante nas creacións literarias de todos os tempos dende a antigüidade clásica. Nesta nota farase unha breve análise comparativa da consumación sexual deste sentimento na película The Shape of Water (2017), de Guillermo del Toro (México, 1964), con respecto a outras narrativas anteriores, profundando tamén noutros aspectos como os rostros do monstro no filme ou a súa proximidade coa fórmula dos contos de fadas. PalABRAS CHAVE: Guillermo del Toro; mitoloxía; monstruosidade; contos de fadas; reescritura.

ABSTRACT The myth of love between the monstrosity and the human being has been a constant feature in literary creations of all times from antique times. This note proposes a brief comparative analysis of sexual experience of lovers in the film The Shape of Water (2017), by Guillermo del Toro (México, 1964), with regard to previous narratives, but also by deepening in other aspects such as the faces of the monster in the movie and its proximity with fairy tales formula.

KEYWORDS: Guillermo del Toro; mythology; monstrosity; fairy tales; rewriting.

\section{Introdución}

A representación da monstruosidade na literatura foi constante na antigüidade clásica e segue moi presente na actualidade, pero os rostros do monstro non se mantiveron invariábeis nin tampouco a maneira na cal o resto de personaxes reaccionaban ante eles. A profesora e investigadora Ana Margarida Ramos, na tese de doutoramento titulada Os monstros na literatura 
de cordel portuguesa do século XVIII (2005: 189-190), realizou unha teorización da monstruosidade onde sostén que "não é uma temática literária do século XVIII (nem sequer dos nossos dias), ainda que uma pesquisa rápida por publicações contemporâneas pareça indiciar a sua extrema actualidade, até em textos que não se inserem, à partida, no fantástico, como é o caso, curiosamente, da literatura infantil". A acepción do termo monstro recollida en The Encyclopedia of Fantasy (1997: 654) editada por John Clute e John Grant indica que "in modern genre fantasy, monsters are a writer's convenience for placing yet another obstacle in the way of the hero's quest", e engade que "most monsters instil dread and are killed to our hero's greater glory, though they may not be inherently evil".

O monstro nace grazas á tendencia natural do ser humano de representar o imposíbel a través do uso activo da imaxinación, de poñer en práctica a súa faceta como "creador" de realidades ficcionais. Ese ser, dotado de sentimentos e intelixencia, remata por verse inmerso en conflitos moi humanos e tende a sufrir por non atopar o seu lugar nun mundo que se lle presenta hostil. En efecto, o medo irracional que nace nas persoas ao identificar algo familiar nun aspecto que lles resulta repulsivo mediante a visión tendenciosa da realidade encamiña ao ser monstruoso a un fatídico final que, en moitas ocasións, só pode resolverse grazas ao amor ou á redención. A partir desta reclamada premisa, o mito de amor co monstro volveuse unha constante en diversas producións até o día de hoxe, sendo reinterpretado polos distintos creadores e dotándoas de certa autonomía con respecto aos hipotextos de partida provenientes de distintas artes.

O cineasta Guillermo del Toro (México, 1964) realiza a súa propia versión do tópico que se estrea en 2017 baixo o título The Shape of Water, un conto de fadas moderno cuxa construción argumental permite a creación de múltiples conexións con textos precedentes que, en todo caso, falan do amor entre o ser humano e o monstro. Ao longo desta nota farase unha análise comparativa da construción narrativa de Del Toro a partir da revisión do conto escrito por Hans Christian Andersen (Dinamarca, 1805-1875), protagonizado por unha serea que sacrifica a súa voz e a súa propia vida por alcanzar o seu amado. Ademais, profundarase nos rostros que adopta a monstruosidade no filme a partir da súa caracterización mediante trazos estéticos e morais, de xeito que se poida entender mellor a forma na que xorde o amor romántico coa protagonista e as diferenzas entre as circunstancias da consumación sexual 
deste sentimento na narrativa de Del Toro e noutras anteriores creadas en contextos de produción moi afastados da contemporaneidade.

\section{The Shape of Water, un conto de fadas moderno no celuloide}

No ano 2017 Guillermo del Toro estreaba unha nova versión cinematográfica do mito de amor coa monstruosidade a modo de conto de fadas moderno para adultos titulada The Shape of Water. O filme, protagonizado por Sally Hawkins, Michael Shannon, Richard Jenkins, Octavia Spencer, Michael Stuhlbarg e Doug Jones dándolle vida ao monstro, resultou ser un éxito comercial e foi enxalzado pola crítica, rematando por levarse distintos premios entre os que destacan os Óscar á mellor película, ao mellor director, á mellor banda sonora e ao mellor deseño de produción, os Globos de Ouro á mellor dirección e banda sonora, os BAFTA ao mellor director, á mellor banda sonora e ao mellor deseño de produción, ademais dos nomeamentos de diversos actores polos papeis interpretados.

A historia está protagonizada por Elisa Espósito, unha muller muda debido a unha ferida nas cordas vocais que lle foi infrinxida de moi pequena antes de ser abandonada xunto ao río, quen leva unha vida rutineira traballando como persoal de limpeza nun laboratorio secreto de investigación estadounidense en Baltimore que intenta levarlle a dianteira aos soviéticos en plena Guerra Fría. Un día calquera chegan ás instalacións un coronel autoritario, déspota, racista e misóxino como xefe de seguridade de nome Richard Strickland e o científico Robert Hoffstetler, que traen consigo un depósito cunha criatura anfibia humanoide extraída dun lodeiro preto ao gran Amazonas onde era venerada polos nativos como un deus. Foi traída ao laboratorio para experimentar con ela e descubrir como funcionaba a súa capacidade de alternar entre dous mecanismos de respiración distintos. Elisa comeza a achegarse á criatura e descobre que presenta intelixencia comunicativa e emocional. Ademais, a rapaza tamén empeza a experimentar sentimentos de cariño que rematan por denotar atracción física. Por esta razón, cando no laboratorio deciden matar a criatura e abrila para explorar o seu interior, Elisa, coa axuda da súa compañeira Zelda, o seu amigo e veciño Giles e o científico que resulta ser un espía dos soviéticos chamado Dimitri, leva a cabo un plan para salvar a criatura e liberala no océano, coa correspondente oposición do coronel Strickland. 
A obra de Del Toro preséntase como unha reescritura libre do clásico conto de fadas de Hans Christian Andersen Den lille Havfrue [A Sereíña ${ }^{1}$, publicado orixinalmente no 1837. Por esta razón, a pesar dos distanciamentos da creación dunha obra para adultos e da contextualización histórica concreta da película que lle permite a Del Toro a realización dunha senda crítica social e política a certas prácticas da época -como a experimentación con seres vivos-, ou a ideoloxías fortemente combatidas até a actualidade -como o machismo, o racismo, a homofobia, o abuso de poder ou a violencia-, tanto o conto de Andersen como o filme presentan algúns elementos comúns:

- Ao comezo da película, a voz en off do narrador testemuña personificado no personaxe de Giles explica que se vai presenciar unha historia que sucedeu fai moito tempo nunha pequena cidade xunto á costa e protagonizada por unha princesa sen voz. No conto de Andersen, a protagonista é a filla menor do rei dos mares, unha nena moi especial, calada, soñadora e reflexiva, pero tamén moi curiosa, que ansiaba con descubrir que había máis alá das profundidades mariñas, en terra firme. Ademais, ela perde a voz cando a bruxa do mar lle corta a lingua a cambio dun remedio que elimine a súa "deformidade" e lle cambie a cola de peixe por dúas pernas humanas, mentres Elisa é muda xa dende o comezo da historia, o que a fixo sentirse diferente e apartada ao longo de toda a súa vida. Precisamente esta sensación de exclusión ou a incapacidade de inserirse nunha construción social coactiva é a que sinte a Sereíña que soña con pertencer a un mundo alleo a ela, Elisa nunha sociedade ruidosa onde as persoas se fan un sitio alzando a voz que ela non posúe, ou Zelda e Giles repudiados pola cor da súa pel e a súa orientación sexual respectivamente.

- A idea de sacrificio tamén é recorrente en ambas narrativas. No caso do conto de Andersen, a bruxa do mar avisa á serea da dor que padecerá ao deixar atrás a súa cola coa esperanza de ter acceso ao seu namorado:

Pero has de saber que eso te producirá tanto dolor como si una afilada espada te rajase. [...] Conservarás la gracia de tus movimientos, ningunha bailarina será tan ágil como tú, pero cada paso que des será como si anduvieras sobre cuchillos afilados y de tus pies manará la sangre. Si estás dispuesta a sufrir todo esto, te ayudaré (Noel Daniel [ed.]: 85).

1 Para a realización deste traballo utilizarase a compilación de contos do autor editada por Noel Daniel e publicada en 2013 por Taschen. 
Na película, Elisa pon en perigo a súa propia vida por salvar a criatura da que se namora, independentemente de que iso pase por deixala ir e afastarse dela para sempre despois de xa ter consumado o seu amor.

- No desenlace de ambas historias acudimos á intervención de elementos alleos á realidade cotiá que actúan como xuíces e xusticeiros. No caso do conto, a divindade cristiá intercede a través da figura das fillas do aire, que recompensan o sacrificio persoal da serea para non danar o seu namorado sabendo que significa o final eterno, e ofrécenlle a posibilidade de construírse unha alma inmortal e ascender aos ceos, o cal lle estaba prohibido como ser híbrido. Ademais, cómpre dicir que a primeira opción de salvación que tiña a serea tamén pasaba polos mesmos termos a través do sacramento do matrimonio, explicado pola súa avoa cando a rapaza lle pregunta se debe resignarse a morrer e desaparecer para sempre:

A no ser que un hombre te ame más que a su padre y a su madre, que te consagre todos sus pensamientos y todo su amor, y que haga que el sacerdote una tu mano derecha con la suya prometiendo serte fiel aquí y en la eternidad. Entonces su alma se derramará en tu cuerpo y participarás en la felicidad de los hombres. Él te dará un alma y, al mismo tiempo, conservará la suya (Noel Daniel [ed.]: 82).

No filme de Del Toro, a propia criatura fantástica resolve o final da historia: despois de recibir os disparos de Strickland, levántase de novo e cura as súas propias feridas, colle a súa namorada, morta pola mesma arma, e lévaa aos fondos mariños onde lle devolve a vida cun bico, transformando as súas cicatrices en branquias que lle permiten vivir baixo a auga.

A película de Del Toro profunda no concepto da monstruosidade e nas formas de representala mediante personaxes en evolución e outros que se descobren realmente segundo avanza a historia. No seguinte apartado enfrontaranse as dúas posibilidades concretas de recreación do monstro na ficción e exemplificarase a dicotomía entre ambas facendo referencia ao filme introducido.

\section{A dicotomía do monstro estético e moral no filme de Del Toro}

Ao longo da historia, os monstros foron utilizados como gardiáns da orde establecida, a vía de escape dos medos dunha comunidade. Estes seres constrúense como a materialidade dos temores de cada sociedade, a encarnación 
do mal que fai tremer aos cidadáns. Deste xeito tamén se transforman nun elemento catártico do subconsciente colectivo: o monstro enfróntase coas leis da normalidade e a súa eliminación permite volver a unha situación estable. Precisamente esa inestabilidade creada pola súa aparición conecta intimamente os conceptos de monstruosidade e do medo irracional: medo ao caos, ao descontrol, á escuridade, ao descoñecido, ao que non se entende, a estar desorientado etc. Ana C. Conde (2004) explica que os medos existen e existirán sempre, pero non se manteñen iguais e vai cambiando a maneira na se manifestan no seno dunha sociedade e, en consecuencia, os rostros do monstro tamén varían: na antigüidade clásica eran seres irracionais, incontrolábeis e aberrantes á vista cuxa derrota pasaba necesariamente pola existencia do seu correspondente heroe; os monstros cristiáns eran os que $o$ fanatismo relixioso vía en calquera ser ou persoa desfigurada e/ou transformada polo pecado e afastada do home creado a imaxe e semellanza de Deus; e as máis recentes representacións da monstruosidade xorden como produto dun mundo dominado pola ciencia e a razón no cal todo pode ser explicado, polo que se agochan dentro da propia persoa: o monstro que levamos dentro.

Pese a que a criatura de Del Toro é venerada polos nativos do Amazonas, a sociedade teoricamente "máis avanzada" que representan os personaxes de contextos máis desenvolvidos, como o estadounidense, repúdiano pola súa aparencia física e aparente salvaxismo. Tan só ven nel un suxeito prescindíbel pero interesante para a ciencia, ao cal infrinxen castigos físicos que poñen fronte a fronte as dúas vertentes da monstruosidade: o monstro en aparencia e o monstro en esencia. En efecto, a análise que se fará en liñas posteriores das representacións do monstro na película precisa dun achegamento ao concepto de monstro que Conde (2004) define dende dúas perspectivas:

- A valoración estética do monstro asociada á idea de beleza: o monstro asóciase á fealdade, como combinación de seres e/ou formas: humano/ animal.

- A valoración moral asociada á idea de liberdade e á escolla entre facer o ben ou o mal: o monstro atenta contra as leis morais e tende a presentarse como un personaxe de dúas caras. A súa aparente normalidade esconde ao monstro que axexa esperando para causar danos sobre as súas vítimas.

A dualidade de representación do monstro no filme xa é adiantada no comezo da obra cando a voz en off advirte sobre a veracidade dos feitos e 
do monstro que intentou destruílo todo. Nun primeiro momento podería parecer que esta referencia é a criatura, dende unha valoración estética da monstruosidade, pero o devir dos acontecementos lévanos a identificar no personaxe de Richard Strickland ao verdadeiro ser horrendo moralmente, ao verdadeiro monstro da ficción. Este personaxe resulta realmente interesante aínda que, ao contrario da protagonista, non sofre ningún tipo de evolución interior. Ao longo do filme imos descubrindo a verdadeira natureza do home, que xa se deixa entrever dende un primeiro momento a través das actitudes que ten cara a Zelda por ser de cor e cara a todas as mulleres pola construción arquetípica e misóxina asentada na mente do coronel. Algunhas das escenas máis rechamantes son o coito de Strickland coa súa esposa, no cal asenta a súa posición dominante sobre o corpo dela e chega a taparlle a boca para facela calar e aumentar o seu propio desfrute. O silencio das mulleres é algo atractivo para el, o cal se reafirma cando acosa a Elisa e lle fai saber que a súa mudez é o trazo que máis lle atrae dela.

A profundidade da que dota Del Toro ao personaxe do coronel pon en primeiro plano a pregunta que levou á aplicación da psicoloxía na investigación criminal: os monstros nacen ou fanse? Non sabemos o suficiente da infancia e o pasado do home como para poder crear un perfil psicolóxico das motivacións e os eventos que o levaron até a situación contida na novela, pero si se evidencia o momento crítico que desencadea a liberación do monstro interior de Strickland: despois de que a criatura fora sacada do laboratorio por Elisa, Strickland é chamado polo superior ao mando para advertirlle de que, se non atopa o ser nun prazo curto de tempo, a súa vida está condenada, pasará ao esquecemento e todo o que fixo até ese momento será insignificante. O coronel móstrase atafegado e encerrado nunha problemática que non sabe ben como solucionar, tratado inxustamente a través da falta de consideración por todo o que el ten feito e sacrificado polo seu país. Pregúntalle ao seu superior cando un home deixa de ser bo e decente, ao que el lle responde que o home bo non é máis que aquel que ten a decencia de non fallar, porque a decencia como sinónimo de bondade non ten importancia real, aínda que sexa a que eles intentan vender á sociedade para poder seguir levando a cabo as barbaridades e os crimes que agochan na súa suposta "integridade moral".

Tamén é posíbel atoparse na ficción outros personaxes que nun primeiro momento parecen pertencer a un lado da balanza e que transitan ou se descobren como antíteses desa caracterización. É o caso do aposto mozo camareiro 
dun bar polo que se sinte atraído Giles quen, cando recibe o coqueteo directo do home, sente asco ante a súa orientación sexual e expúlsao do local, ao mesmo tempo que tamén bota de malas formas a unha parella de cor. Por outra parte, o personaxe do científico, que remata sendo un espía infiltrado, parece claramente un personaxe antagónico, ben como estadounidense ou como soviético, pero a humanidade contida dentro del (entendida como a compaixón e benevolencia cara aos demais) faino evolucionar e remata participando no plan de liberación da criatura aínda correndo o risco de perder a vida. No caso de Giles, Zelda e a propia Elisa, o máis destacábel deles é a evolución que sofren e a valentía que demostran nas súas accións ilegais a favor da xustiza e os enfrontamentos con representantes de estamentos poderosos como o goberno estadounidense.

\section{A consumación sexual do amor romántico co monstro en diversas narrativas}

O elemento distintivo máis característico da interpretación do mito de amor coa monstruosidade no filme de Del Toro é o xeito no que se consuman sexualmente os sentimentos que Elisa comeza a sentir pola criatura. No monográfico escrito por Antonio Mora (2007) sobre os monstros e a alteridade, o investigador indica que a monstruosidade tende a ser imaxinariamente visual, un ser particularmente molesto á vista e desprezábel dende o punto de vista do desexo: "lo monstruoso no es deseable, rompe el orden de lo libidinal, y se instaura como choque de la visión directa, como antiestético, inmoral y horrororo". Elisa asústase no seu primeiro encontro coa criatura, mais tamén comeza dende ese momento un continuo desexo de descubrimento que, dende a curiosidade, lévaa a interactuar con ela. A partir de aí, a identificación que fai a moza cun ser que non encaixa, cun "patiño feo" que lle recorda a ela mesma, fan xurdir o amor e a atracción sexual que remata por consumarse.

Para enxalzar o característico desta maneira de desenvolver o mito, nas seguintes liñas botarase a vista atrás cara a outras narrativas moi coñecidas e de distintos momentos históricos, analizando en profundidade como se resolveu a consumación sexual do amor entre os suxeitos e a influencia do contexto de creación das obras. Para isto, farase especial referencia a tres narrativas: o nacemento do minotauro de Creta, cuxa versión máis concreta se atopa na 
Biblioteca Mitológica de Apolodoro (s. I-II d.C.)2 o mito de amor entre Psiche e Cupido, recollida por Apuleyo na obra El Asno de Oro (s. II d.C.) $)^{3}$, e a reescritura do mito que fai Madame Leprince de Beaumont na novela La Belle et la Bête, publicada orixinalmente no $1756^{4}$, a versión máis coñecida do conto até a actualidade e que serviu de base para as distintas reescrituras.

Segundo Apolodoro, Minos, rei de Creta, prometéralle ao deus Posidón un sacrificio no seu nome polo que lle enviou un magnífico touro saído do mar. No obstante, o rei quedou asombrado co animal e decidiu incorporalo como semental ao seu rabaño, cometendo o peor pecado da sociedade clásica: býbris; é dicir, un intento de ir en contra dos designios dos deuses. Posidón decidiu vingarse facendo que Pasífae, muller de Minos, se namorara do animal. $\mathrm{O}$ feitizo de amor foi tan forte que a muller acudiu ao inventor da cidade, Dédalo, quen lle construíu unha vaca de madeira dentro da cal se colocaría a raíña. Así puido consumar sexualmente os seus sentimentos pola criatura e, como consecuencia, dou a luz ao famoso minotauro de Creta. Aínda que para a sociedade contemporánea este evento poida resultar unha aberración, o certo é que a zoofilia era algo aceptado na antigüidade clásica e recorrente en moitos mitos, aínda que esta perspectiva social cambiou completamente coa chegada do cristianismo. En efecto, algúns exemplos serían as metamorfoses de Zeus en animais para poder raptar e xacer con distintas mortais ou a gran apetencia sexual dos sátiros que acompañaban ao deus Dioniso.

O seguinte mito, escrito por Apuleyo, fala da princesa Psiche, a pequena e máis fermosa de tres irmás ben parecidas. Era tan bela que a xente a veneraba como se fose a reencarnación da propia deusa Venus e ninguén se achegaba a ela nin se atrevía a cortexala. Estas comparacións fixeron xurdir a ira da deusa, que chamou polo seu fillo Cupido e ordenoulle que lanzara unha das súas frechas á rapaza para que se namorara "de hombre de poco y bajo estado, al cual la Fortuna no dio dignididad de estado, ni patrimonio ni salud. Y sea tan bajo que en todo el mundo no halle otro semejante a su miseria" (Apuleyo, 2013: 185). O pai de Psique, preocupado porque ningún home da realeza mostrara

2 Para a realización deste traballo utilizarase a edición publicada por Alianza no 2016, traducida por Julia García Moreno.

3 Para a realización deste traballo utilizarase a edición publicada por Alianza no 2013, traducida por Diego López de Cortegana.

4 Para a realización deste traballo utilizarase a edición publicada por Reino de Cordelia no 2013, cuxa tradución e prólogo foron feitos por Luis Alberto de Cuenca. 
interese real pola súa filla e por se iso tiña que ver co designio dos deuses, consultoulle ao oráculo antigo de Apolo na cidade de Milesia suplicándolle que lle dera casa e marido á súa filla, ao que o deus respondeu:

"Pondrás esta moza adornada de todo aparato de llanto y luto, como para enterrarla, en una piedra de una alta montaña y déjala allí. No esperes yerno que sea nacido de linaje mortal; mas espéralo fiero y cruel, y venenoso como serpiente: el cual, volando con sus alas, fatiga todas las cosas sobre los cielos, y con sus saetas y llamas doma y enflaquece todas las cosas; al cual, el mismo dios Júpiter teme, y todos los otros dioses se espantan, los ríos y lagos del infierno le temen" (Apuleyo, 2013: 187).

O pai de Psiche deixouna no alto dunha montaña onde foi collida por un manso vento que a deixou nun prado verde e fermoso. Cando a rapaza espertou deuse conta de que se atopaba nun palacio que parecía demasiado divino para ter sido construído por mortais e dirixiuse a descansar guiada por unhas voces que dicían ser as súas servidoras e ela a dona de todo. Durante a noite, o marido da rapaza, oculto entre as sombras, chegou ao leito e xaceu con Psiche, marchando antes do amencer. Así o fixo outras noites até que a estrañeza se tornou pracer e naceu o amor. Non obstante, a voz do marido faloulle do malestar da súa familia despois de que ela marchara e sumiu a moza nunha profunda tristeza, a cal fixo que el lle permitira traer as súas irmás ao seu palacio para informalas de que estaba a salvo e feliz. Cando chegaron, as irmás sentiron envexa de todo o que tiña Psique e insistiron en saber quen era o seu esposo, ao que ela respondeu cunha invención. A noite que Psiche volveu atoparse co marido na escuridade, el advertiulle sobre as malas intencións das súas irmás e o interese malvado que tiñan en que ela lle vise a cara, comunicándolle que no seu ventre había un neno que, se inflixía as normas, deixaría a divindade para ser un simple mortal. Mais as irmás non cesaron no seu intento de malograr o futuro da rapaza e remataron por sacarlle a verdade e convencela de que, seguindo a profecía de Apolo, o seu marido era unha serpe grande e velenosa. Ofrecéronlle un candil que debía acender na escuridade da noite para descubrir o aspecto do esposo e matalo cun coitelo. A pesar das dúbidas da muller polo amor que sentía cara ao ser que compartía cada noite o leito con ela, seguiu o plan e, ao acender o candil, comprobou que o seu marido era o propio deus Cupido, quen fora en contra dos designios da súa nai e rematara por namorarse da moza. Deste xeito, o deus fuxiu do lugar e comezaron unha serie de probas e penitencias que a moza foi cumprindo até volver atoparse co seu marido e desfrutar do seu amor felizmente. 
O máis interesante desta obra, tendo en conta os obxectivos desta nota, é a controversia que sinte Psique ante a posibilidade de que o marido que ama e do cal espera un fillo sexa un monstro: "En fin, lo que más la fatigaba era que en un mismo cuerpo aborrecía a la serpiente y amaba a su marido" (Apuleyo, 2013: 210). En efecto, a consumación sexual do amor sucede sen ter constancia da forma física do suxeito e, cando ela cre saber que se trata dunha figura aberrante, decide ir en contra dos seus sentimentos e acabar coa criatura. $\mathrm{O}$ plan é detido cando se confirma a extrema beleza do namorado, o propio deus Cupido, porque o amor e a atracción cara a un ser que non é fermoso é incompresible. En efecto, cómpre destacar que, no caso do touro de Posidón, trátase dun ser de gran beleza aínda que dentro da súa condición animal.

Cando Madame Leprince de Beaumont recolle a tradición do mito de amor co monstro e publica a súa coñecida versión, o seu obxectivo era crear un relato que alentara ás mozas da corte francesa a aceptar de mellor grao os matrimonios de conveniencia con homes moito máis maiores que elas. María Tatar $\left(2012^{5}\right.$ : 62), na súa recompilación dos contos de fadas anotados, explica que a autora transmite que a receita para o matrimonio triunfante non reside na "beleza" nin o "enxeño", desaprobando a paixón do amor romántico e sostendo que os sentimentos de "respecto, amizade e gratitude" son prioritarios: "recomienda a las mujeres la obediencia, la abnegación y una forma de amor basada más en la gratitud que en la pasión". De maneira contraditoria, a novela parece criticar estas unións ao mesmo tempo que reivindica a busca interior dun ser menos repulsivo do que se mostra en aparencia, repercutindo tamén no benestar da doncela.

A novela de Beaumont preséntanos a unha rapaza coñecida como A Nena Bela pola súa fermosura, a filla menor de seis (tres homes e tres mulleres) dun mercador moi rico. As outras irmás envexábana porque era máis guapa. Ademais, tamén era mellor persoa, máis humilde e mellor filla. Cando o pai cae en desgraza toda a familia trasládase ao campo e Bela desfruta do duro traballo alí. O mercador parte nunha viaxe que pode devolverlle a súa prosperidade e as fillas avarentas pídenlle que volva con riquezas e bonitos vestidos, mentres Bela só lle pide unha humilde rosa. O mercador volve igual de pobre e, polo camiño, atopa un castelo onde se guarece da neve. Alí aparecen todos os víveres que necesitaba e recibe un bo trato, mais, cando xa marchaba,

5 A primeira edición foi publicada no 2002. 
arrinca unha rosa e aparece unha horríbel besta que o acusa de roubarlle o máis prezado para el. Finalmente déixao ir a cambio de que mande a unha das fillas no seu lugar. Aínda que o pai non quería sacrificala, Bela viaxa ao palacio e comeza a vivir chea de comodidades desfrutando da compañía da Besta, pola cal sente un profundo cariño e comparte moitas conversacións amigábeis. Cando Bela sabe que o seu pai está enfermo acude a visitalo coa promesa de volver coa Besta. As irmás, que envexan a felicidade da súa irmá e se senten desgraciadas cos seus respectivos matrimonios, aprovéitanse da bondade de Bela e convéncena para quedarse máis do pactado. Cando a rapaza soña coa Besta moribunda utiliza o anel máxico que lle ofrecera para volver e ir no seu auxilio. De regreso, atópao case morto e arrepíntese de non ter casado con el polo seu aspecto exterior. $\mathrm{O}$ pesar que sinte ao velo nesa situación faille saber que, na realidade, está namorada del. Esta confesión rompe o maleficio que unha fada lle lanzara ao príncipe e ao seu reino e recobra a súa fermosa forma humana, dando así lugar ao final feliz dos namorados e ao castigo das malvadas irmás transformadas en estatuas.

O máis interesante con respecto á caracterización do monstro na novela de Beaumont é a diferenciación que se fai entre o monstro e a besta, a cal se desliga das palabras da Bela cando a Besta lle fala da súa condición:

- [...] Decidme, ¿no es verdad que me encontráis feo?

- Cierto es -dijo Bella-, ya que soy incapaz de mentir, pero creo que sois muy bueno.

- Tenéis razón -dijo el monstruo-. Pero es que, además de ser feo, carezco de ingenio: sé muy bien que no soy más feo que una bestia.

-No se es una bestia -repuso la Bella- cuando uno dice que cree no ser ingenioso. Un tonto nunca diría eso (De Beaumont, 2013: 37).

En efecto, a monstruosidade da Besta sostense a partir da súa fealdade, pero Bela oponse a atribuírlle a condición de besta no sentido de salvaxe, malvado ou incontrolable. Ademais, Bela remata por facer unha referencia explícita á diferenciación entre o monstro estético e o moral:

— ¡Ah, señora! -respondió Bestia-. Sí, tengo buen corazón, pero soy un monstruo.

- Hay muchos hombres que son más monstruosos que vos -dijo Bella-, y yo os quiero más con vuestra apariencia que a aquellos que, debajo de una apariencia humana, ocultan un corazón falso, corrompido, ingrato (De Beaumont, 2013: 40). 
A fealdade da besta é a que produce o rexeitamento continuo de Bela á proposición de matrimonio, aínda que con pesar polo profundo afecto que lle profesa. É necesario que a rapaza vexa a posibilidade de perdelo para sempre para descubrir os seus verdadeiros sentimentos e aceptar o amor romántico cara a un ser cuxa fealdade lle impide sentir atracción sexual. De feito, a reflexión final de Bela non fai ningún tipo de referencia ao aspecto carnal:

-No, mi querido Bestia, no moriréis -le dijo Bella-. Viviréis para convertiros en mi esposo. Desde este momento os doy la mano y juro que seré solamente vuestra. ¡Ay! Creía no sentir más que amistad por vos, pero el dolor que experimento me hace ver que no podría ya vivir sin veros (De Beaumont, 2013: 48).

A decisión de Bela non só ten consecuencias positivas para a besta, que volve ser un fermoso príncipe, senón tamén para a propia rapaza, as cales lle son indicadas pola fada: "habéis preferido la virtud a la belleza y al ingenio, y merecéis encontrar todas esas cualidades reunidas en una misma persona" (De Beaumont, 2013: 51-52). A historia, creada nun contexto dominado polo catolicismo, non podía permitir que a consumación sexual se dera cun ser que non presentaba unha imaxe semellante á dos humanos e a súa metamorfose final é un requisito explícito para o avance do sacramento matrimonial e a constitución dun núcleo familiar aceptábel para a época.

Resulta evidente que a coacción social e as limitacións que o propio contexto presentaba na construción das narrativas non é a mesma que ten Del Toro en pleno século XXI. A contemporaneidade e a liberación relixiosa permítenlle mostrar unha protagonista que inclúe na súa rutina diaria a masturbación, que desfruta do sexo coa criatura de maneira libre e que despois o comenta coa súa amiga Zelda. Estes eventos serían unha aberración para a mentalidade da época na que se contextualiza a historia, pero, grazas a esta rotura e oposición valente que fan Elisa e os seus aliados ao "politicamente correcto", o público actual identificouse moito co filme até convertelo no maior éxito do cineasta.

\section{Conclusión}

O medo irracional producido pola monstruosidade fai que as persoas sexan máis susceptibles de ser controladas e guiadas nunha dirección deseñada por uns poucos. Deste xeito, o monstro adquire o rostro do outro, do dife- 
rente, a partir dunha interpretación manipulada da realidade. A formación integral da persoa a través de axentes de socialización como a literatura ou o cine é unha das maneiras máis eficaces de deixar de ver o diferente como inimigo e de asignarlle novas funcións narrativas á monstruosidade que profunden e exploren os límites da súa existencia como paradigma da alteridade. Así poderase descubrir se se trata realmente do elemento que debe ser transformado e eliminado ou unha simple distracción do verdadeiro perigo.

A obra de Del Toro ilustra perfectamente esta idea final ao mesmo tempo que nos permite constatar varias hipóteses con respecto ao mito do amor co monstro baseadas na maneira de resolver este sentimento a través da consumación sexual:

- Existe unha diferenciación clara entre as dúas vertentes ou posibilidades de concreción da monstruosidade, dende o valor estético e o valor moral, que cambian por completo o desenvolvemento dos acontecementos e a natureza dos personaxes, até o punto de transformar o monstro estético no obxecto de desexo da protagonista.

- O contexto de produción de calquera obra, literaria ou fílmica, determina a maneira na que se constrúe unha narrativa, que se erixe como unha representación cultural dun determinado momento histórico a partir da especificidade do receptor implícito, dándolle cabida ao cineasta á consumación sexual do amor romántico representado no celuloide con sutileza e normalidade.

- A intertextualidade con obras anteriores é un dos recursos fundamentais que usan os creadores actuais para a elaboración de novas obras que, aínda que sexan realizadas para adultos, poden partir de hipotextos literarios do sistema infantil e xuvenil como a fórmula dos contos de fadas ou a historia da Bela e da Besta.

Rocío G-Pedreira

CIEC-IE-Universidade do Minho/ ICE-Universidade de Santiago de Compostela

\section{Referencias bibliográficas}

Antonio Mora, Maynor. 2007. Los monstruos y la alteridad: hacia una interpretación crítica del mito moderno del monstruo. Costa Rica: Universidad Nacional de Costa Rica. 
Apolodoro. 2016. Biblioteca Mitológica. Madrid: Alianza Editorial.

Apuleyo. 2013. El Asno de Oro. Madrid: Alianza Editorial.

Clute, John e Grant, John (eds.) (1997). The Encyclopedia of Fantasy. Gran Bretaña: Orbit.

Conde, Ana C. 2004. "Estudio sobre una deriva conceptual: del Monstruo al otro a través de la literatura", en A Parte Rei: revista de filosofia, 34, pp. 1- 17. http:// serbal.pntic.mec.es/\% 7ecmunoz11/conde34.pdf [Consulta 01/08/2019].

Daniel, Noel (ed). 2013. Los cuentos de Hans Cbristian Andersen. Alemania: Taschen.

De Beaumont, Madame Leprince. 2013. La Bella y la Bestia. Madrid: Reino de Cordelia.

Margarida Ramos, Ana. 2005. Os monstros na literatura de cordel portuguesa do século XVIII [Tese de Doutoramento]. Portugal: Universidade de Aveiro. https://ria. ua.pt/bitstream/10773/4845/1/2007000114.pdf [Consulta: 01/08/2019].

Tatar, Maria. 2002. Los cuentos de hadas clásicos anotados. Barcelona: Editorial Crítica.

\section{Filmografía}

The shape of Water. 2017. Dirección: Guillermo del Toro. Producción: Fox Searchlight Pictures e TSG Entertainment. 119 min. 